\title{
Análise do Discurso sobre Redução de Danos num CAPSad III e em uma Comunidade Terapêutica
}

\author{
Bruno Carvalho ${ }^{1}$ \\ Curso de Psicologia, Universidade Potiguar, Natal, RN, Brasil \\ Magda Dimenstein \\ Departamento de Psicologia, Universidade Federal do Rio Grande do Norte, \\ Natal, RN, Brasil
}

\begin{abstract}
Resumo
A proposta da Redução de Danos (RD) tem sido utilizada na elaboração de políticas de saúde que não estejam focadas somente na abstinência de substâncias psicoativas. O preconceito moral e a resistência dos profissionais em trabalhar com a proposta é uma dificuldade para sua implementação. Este estudo objetiva investigar concepções e práticas de RD num Centro de Atenção Psicossocial Álcool e Drogas III e uma Comunidade Terapêutica. Trata-se de um estudo qualitativo que realizou 21 entrevistas semiestruturadas com profissionais e 05 rodas de conversa com usuários. Identificamos em ambas as instituições que a RD é uma proposta que recebe pouco apoio e não está incorporada à rotina dos serviços, sendo vista como uma estratégia menos complexa e mais barata. A RD não é operacionalizada no cotidiano pelos profissionais que não informam os usuários sobre diversas possibilidades de tratamento no sistema de saúde. Os usuários mostram-se receptivos à RD no enfrentamento das dificuldades e riscos decorrentes do abuso de substâncias psicoativas; reconhecem os efeitos positivos dessa proposta, especialmente no que diz respeito à adesão ao tratamento e recaídas.
\end{abstract}

Palavras-chave: Redução de danos, álcool, drogas, Centro de Atenção Psicossocial, comunidade terapêutica.

\section{Discourse Analysis about Harm Reduction in a CAPSad III and a Therapeutic Comunity}

\begin{abstract}
The Harm Reduction proposal has been used for establishing health policies that aren't solely focused on abstinence from psychoactive substances. The moral prejudice and resistance presented by professionals when dealing with the proposal is a difficult in its implementation. We set to investigate the mindset and practice of Harm Reduction in a Psychosocial Care Center for alcohol and drugs (CAPSad III) and in a therapeutic community. This is a qualitative study with 21 semi-structured interviews conducted with the said professionals and 5 group talks with users. We identified in both institutions that Harm Reduction is an idea that receives low support and is not fully incorporated to the service routine. It is also seen as a less complex and cheaper strategy. Harm Reduction is not an operational part of the professionals' repertoire, and they do not inform users of many possible treatments within the health system. The users
\end{abstract}

Endereço para correspondência: Rua do Diamante, 313, Apto. 1, Bairro Lagoa Nova, Natal, RN, Brasil 59.076260. E-mail: brunoakpereira@gmail.com

Esse artigo origina-se de uma pesquisa de mestrado intitulada "A Redução de Danos no atendimento especializado em álcool e outras drogas”, apresentada ao Programa de Pós-Graduação em Psicologia da Universidade Federal do Rio Grande do Norte. 
show themselves to be receptive toward Harm Reduction when it comes to facing the struggles and risks that come from abusing psychoactive substance; they also recognize the positive effects of the Harm Reduction proposal, especially when it comes to adherence to treatment and relapses.

Keywords: Harm reduction, alcohol, drugs, Psychosocial Care Center, therapeutic community.

\section{Analisis del Discurso sobre la Reducción de Daños en un CAPSad III y en una Comunidad Terapéutica}

\section{Resumen}

La propuesta de la Reducción de Daños (RD) ha sido utilizada para la elaboración de políticas de salud que no estén enfocadas solamente en la abstinencia de sustancias psicoactivas. El preconcepto moral y resistencia de los profesionales en trabajar con la propuesta es una dificultade para su implantación. Nos proponemos investigar concepciones y prácticas de $\mathrm{RD}$ en un Centro de Atención Psicosocial a Alcohol y Drogas III y una Comunidad Terapéutica. Se trata de un estudio cualitativo que realizó 21 entrevistas semiestructuradas con profesionales y 05 ruedas de conversación con usuarios. Identificamos en ambas instituciones que la RD es una propuesta que recibe poco apoyo y no está incorporada a la rutina de los servicios. Es vista como una estrategia menos compleja y más barata. La RD no es operacionalizada en el cotidiano por los profesionales, que no informan a los usuarios sobre diversas posibilidades de tratamiento en el sistema de salud. Los usuarios se muestran receptivos a los principios de la RD en el enfrentamiento de las dificultades y riesgos derivados del abuso de sustancias psicoactivas; reconocen los efectos positivos de la propuesta de $\mathrm{RD}$, especialmente en lo que tiene que ver con la adhesión al tratamiento y recaídas.

Palabras clave: Reducción de daños, alcohol, drogas, Centro de Atención Psicosocial, comunidad terapéutica.

Atualmente as políticas relacionadas ao controle de drogas no mundo passam por mudanças, e nessa direção, diversos países da América Latina e Europa alteraram alguns de seus procedimentos legais e/ou terapêuticos (European Monitoring Centre for Drugs and Drug Addiction, 2005; Jelsma, 2009), sendo o Uruguai o principal expoente desse processo ao tornar-se o primeiro país do mundo a ter um sistema totalmente regulamentado de produção e consumo de maconha. Esse processo advém da crítica de diversos setores da sociedade que avaliam o atual sistema de proibição e controle de entorpecentes como ineficaz em conter os problemas sanitários e sociais associados ao uso de substâncias psicoativas (SPA's), fato que para alguns avaliadores produziu consequências piores do que o próprio uso abusivo de drogas. Esse sistema é violador dos direitos humanos e gera violência (Werb, Rowell, Guyatt, Kerr, Montaner, \& Wood, 2011), principalmente contra homens jovens e pobres, é uma ameaça à democracia em algumas regiões e responsável pela manutenção de organizações criminosas nacionais e internacionais (Bastos, Karam, \& Martins, 2003; Comissão Global de Políticas Sobre Drogas, 2011; Nadelmann, 2005).

A Redução de Danos (RD) foi o primeiro movimento a criticar o modelo internacional de proibição às drogas que obteve respaldo mundial. Essa nova maneira de entender o consumo de SPA's teve início nos anos 1980 com a criação dos programas de troca de seringas para conter a disseminação de hepatites, e, posteriormente, HIV e outras doenças infectocontagiosas, entre usuários de drogas injetáveis. Não há um conceito único de RD, refere-se, basicamente, às políticas e programas de intervenção, cujo objetivo é minimizar riscos, sem necessariamente diminuir o consumo individual de substâncias psicoativas. Para tanto, busca diferenciar repercussões na saúde dos indivíduos e suas relações 
comunitárias, bem como custos econômicos e impactos sociais relacionados às políticas sobre drogas (Newcombe, 1992).

Essas distinções apontam a variedade de intervenções que se encontram baseadas em seus princípios o que a tornou, portanto, um conceito fundamental no campo da saúde comunitária, além da possibilidade de ser aplicado a vários problemas de saúde e não somente às drogas ilícitas (Fontanella \& Turato, 2005). Entendemos que a RD não é somente um conjunto de técnicas no campo da saúde, mas, uma iniciativa inovadora de atenção às pessoas com problemas relacionados ao abuso de SPA's, baseado nos direitos humanos, singularidade e vontade dessas pessoas (Canadian AIDS Society, 2008). Tal iniciativa propõe o resgate da dimensão de liberdade em um campo historicamente marcado pela imposição moral e controle dos comportamentos como base dos tratamentos à dependência química.

A RD se propõe a romper com os modelos anteriores de estigmatização das drogas, a fim de suscitar o surgimento de outras possibilidades terapêuticas em relação ao uso e dependência. Ela considera que as SPA's fazem parte da vida e da cultura humana há milênios, sendo usadas com finalidades terapêuticas e lúdicas, logo, propor um mundo livre das drogas é uma meta irrealista (Hunt, 2003). Dessa maneira, a RD não exige abstinência como pré-requisito para permanência em programas de atenção à saúde, mas busca criar estratégias não coercitivas para adesão aos serviços, estabelecer uma relação acolhedora dos profissionais com os usuários (Canadian AIDS Society, 2008), além de incluí-los como partícipes na produção de cuidado (Souza, 2007).

Portanto, a RD não está focada na aprovação ou não do uso, uma vez que suas intervenções não se fundamentam em questões morais. A pessoa que faz uso de substâncias lícitas ou ilícitas é um ser humano e antes de tudo deve ter seus direitos respeitados e, inclusive, sua decisão por manter o consumo. Considera que os usuários de SPA's e seus familiares são capazes de tomar decisões, ponto central para constituição de uma relação com os profissionais de saúde menos hierárquica e mais acolhedora
(Canadian AIDS Society, 2008; Fontanella \& Turato, 2005).

Essa perspectiva vem confrontar a ideia que consumidores de SPA's não teriam condições de refletir sobre seu consumo e nem de mudar por vontade própria seus padrões de uso. Estudos empíricos atuais têm demonstrado que usuários considerados dependentes químicos de cocaína e metanfetamina são capazes de tomar decisões racionais frente a situações de consumo, bem como, controlar o sentimento de "fissura" ( $\mathrm{cra}$ ving) utilizando estratégias cognitivas (Lopez, Onyemekwu, Hart, Ochsner, \& Kober, 2015; Vadhan, Hart, Haney, Gorp, \& Foltin, 2009).

Historicamente, o Brasil, e pode-se dizer a América Latina, sempre estiveram alinhados às políticas proibicionistas e suas intervenções seguiam o modelo médico-jurídico (Rodrigues, 2006). Nele, usuários de SPA's são considerados doentes ou criminosos, logo, estão destinados à internação psiquiátrica ou à prisão. Dessa forma, a RD encontra-se na articulação entre clínica e política, uma vez que desde seu início traz uma contestação da política hegemônica de criminalização ao uso de drogas (Passos \& Souza, 2011). Convém apontar que, apesar dos riscos à saúde que o consumo excessivo de determinadas SPA's pode oferecer, não se deve ocultar as estratégias de poder e controle social que operam por meio da legitimidade das políticas públicas relacionadas às drogas, especialmente as de cunho emergenciais, de "tolerância zero" ou policialescas (Alarcon, 2012; Escohotado, 1998; Levine, 2003; Passos \& Souza, 2011).

A partir da década de 1980, com o surgimento da AIDS e sua disseminação entre usuários de drogas injetáveis, a política brasileira de drogas sofreu transformações e algumas ações começaram a ser postas em prática pelo Ministério da Saúde. A RD surgiu como uma ação focada na prevenção de infecções entre usuários de drogas injetáveis, com uma intervenção concreta, a troca de seringas e agulhas (Souza, 2007). Porém, durante a década de 1990, os usuários brasileiros modificaram seus padrões de consumo e passaram do uso da cocaína injetável para a fumada (crack), mudança observada em diversos países do mundo, fazendo com que os programas 
de troca de seringas perdessem sua força. Isso compeliu, mais uma vez, o governo brasileiro a propor novas estratégias e, no início dos anos 2000, a RD sofre alterações, passando a ser uma proposta ampliada de produção de saúde. Dessa forma, ganha legitimidade e passa a ocupar lugar central nas políticas relativas ao consumo de álcool e drogas (AD).

Atualmente, o Ministério da Saúde brasileiro trabalha na construção de uma rede de serviços sob os princípios do Sistema Único de Saúde e da reforma psiquiátrica, culminando na Portaria $\mathrm{n}^{\circ} 3.088,23$ de dezembro de 2011 que institui a Rede de Atenção Psicossocial (RAPS) para pessoas com necessidades decorrentes do uso de AD. Essa rede prevê intervenções organizadas em sete níveis, que vão desde a atenção básica às ações de reinserção social. Na RAPS, os Centros de Atenção Psicossocial (CAPS) assumem uma função central, tanto na articulação dos diversos serviços que a compõe, quanto como local de referência no cuidado para usuários e familiares. Existem 2.678 CAPS no país (Data SUS, 2015), desses 308 são unidades do tipo CAPSad, para usuários de álcool e outras drogas.

A partir dessa mesma portaria, as Comunidades Terapêuticas (CT's) passam a fazer parte da RAPS como locais de atenção residencial de caráter transitório. Segundo a Resolução CONAD N ${ }^{\circ}$ 01/2015 do Conselho Nacional de Políticas Sobre Drogas (CONAD) as CT's devem se adequar às diretrizes que preconizam o internamento voluntário e somente após a avaliação de algum serviço de saúde ou profissional habilitado, bem como realizar uma articulação com os diferentes serviços da saúde e assistência social que fazem parte do seu território. Contudo, as CT's, em sua maioria, não têm articulação com os demais serviços da RAPS e buscam criar estratégias próprias para que seus integrantes permaneçam em contato com elas, mesmo após a internação (Dias, 2012). No Brasil, geralmente, são criadas sem a orientação de profissionais, não seguem os parâmetros do SUS, são organizadas por voluntários, sem exigência de formação técnica, trabalham com internações prolongadas e têm como diretriz institucional a religião cristã. No censo realizado em 2013 pela Secretária
Nacional de Políticas sobre Drogas foram registradas 1.846 CT's no país, contudo em pesquisa na página online do programa "Crack é possível vencer" o número apresentado diminui para 336 comunidades, com um total de 7.541 vagas. Nas duas estimativas as CT's superam numericamente os CAPSad, indicando que a atenção aos usuários de $\mathrm{AD}$ tem se expandindo intensamente em instituições não reguladas pelo Estado brasileiro, evidenciando as ambivalências que circundam essa temática no país.

Assim, pela importância da RD no contexto mundial de atenção aos usuários de $\mathrm{AD}$, por ser a diretriz oficial da política de saúde mental brasileira desde 2003 para lidar com o consumo de SPA's (Ministério da Saúde, 2004), pelas resistências e comportamentos moralizantes detectados entre os profissionais da saúde (AmaralSabadini, Saitz, \& Souza-Formigoni, 2010), o presente estudo buscou conhecer concepções e práticas de RD entre profissionais e usuários de duas instituições de atendimento especializado a usuários de $\mathrm{AD}$, sendo essas: um CAPSad III (aberto 24hs) e uma Comunidade Terapêutica.

\section{Método}

\section{Participantes}

A amostra total incluindo as duas instituições ficou composta de 21 profissionais e 63 usuários. No CAPSad III foram 16 trabalhadores: coordenador (psicólogo), administrador (pedagogo), enfermeiro, educador físico, nutricionista, assistente social, clínico geral, psiquiatra, farmacêutico, redutor de danos, psicólogo e cinco técnicos em enfermagem. O critério de inclusão foi contemplar, ao menos, um entrevistado de cada categoria profissional e realizar as entrevistas até atingir a saturação das informações. Tendo em vista o número restrito de trabalhadores da CT, não houve critério para exclusão e nenhum se recusou a participar da pesquisa. Dessa forma, foi possível entrevistar todos os integrantes dessa equipe e a amostra ficou composta de 05 trabalhadores que ocupavam funções de coordenação, sendo essas: o presidente; o "padrinho", segundo na hierarquia institucional; e os três coordenadores, que ainda são internos, mas 
estavam no último mês da vivência na comunidade. Em relação aos usuários do CAPSad III, 33 pessoas se disponibilizaram a participar da pesquisa, das quais somente duas eram do sexo feminino. Na CT, os 30 internos da instituição participaram, sendo todos do sexo masculino.

\section{Instrumentos}

As ferramentas metodológicas utilizadas para atingir os objetivos da pesquisa foram: entrevista semiestruturada com profissionais, rodas de conversa e ficha sócio demográfica com usuários. A entrevista semi estruturada permite o acesso à informações mais detalhadas e auxilia, tanto ao entrevistador quanto ao entrevistado, na organização e no encadeamento da argumentação, contribuindo para que os objetivos da pesquisa sejam melhor investigados (Breakwell, Fife-Schaw, Hammond, \& Smith, 2010). A roda de conversa é uma metodologia participativa que busca criar condições dialógicas para a reflexão sobre informações, experiências, saberes e atitudes de um grupo. Caracteriza-se por ser uma intervenção pontual e tem sido aplicada em diversos contextos quando o objetivo é promover uma reflexão adequada e construída com base nas características e necessidades de determinado grupo. (Afonso \& Abade, 2008).

Foram utilizados dois roteiros de entrevista, um com coordenadores das instituições e outro com os demais profissionais. Com os coordenadores, buscou-se reconstituir a história da instituição, caracterizar o seu funcionamento, explicitar os objetivos das intervenções terapêuticas e como são utilizados os conceitos da RD na construção de suas práticas. O roteiro que direcionou as entrevistas com os técnicos tinha como foco as atividades desenvolvidas no serviço, suas concepções e ações em RD, avaliação da RD, dificuldades em relação à RD e como ela opera na sua rotina de trabalho. As entrevistas foram gravadas sem identificação, transcritas e tiveram duração média de 45 minutos. Foram realizadas cinco rodas de conversa, três no CAPSad III e duas na CT, com duração média de 55 minutos cada. Investigaram-se os seguintes aspectos: a avaliação da instituição pelos usuários, suas concepções sobre RD e as suas estratégias pessoais de RD. As rodas de conversa foram gravadas e transcritas para serem analisadas posteriormente, e não houve identificação dos nomes dos participantes. Aos usuários também foi requisitado o preenchimento de uma ficha sócio demográfica com dados referentes às condições sociais e financeiras, além da identificação do consumo de qual SPA o fez procurar o serviço e quantas vezes já esteve em tratamento. No total foram preenchidas 56 fichas, utilizadas na descrição da amostra dos usuários, essa etapa durava entre 15 e 20 minutos.

\section{Procedimentos Metodológicos}

Nesse estudo foram seguidos os preceitos éticos e de garantia do caráter anônimo e voluntário de participação, o termo de consentimento livre e esclarecido era apresentado e assinado no começo de cada atividade da coleta de dados, momento em que eram explicados os objetivos da pesquisa e solicitada permissão para uso do gravador. Somente após o aceite dos participantes iniciava-se a coleta. A pesquisa no CAPSad III iniciou com a apresentação do projeto à coordenação de saúde mental do município, que concedeu autorização para sua continuidade. Em seguida, realizou-se entrevista com a coordenação do próprio serviço. Após esse momento inicial, foram feitas dez visitas a instituição com duração média de três horas, compreendendo um período de 30 dias entre a primeira e a última visita.

$\mathrm{Na} \mathrm{CT}$, o contato inicial foi pelo telefone, momento em que foi apresentada a pesquisa e questionado se a comunidade poderia ser um dos locais para a coleta de dados. Após receber a autorização, organizou-se a ida a campo para residir dentro da comunidade por um período de quatro dias, no qual o pesquisador participou de todas as atividades da rotina diária da comunidade, trabalho, oração e socialização. Após um curto período de entrada nas instituições, utilizado para conhecer a rotina e as pessoas que compunham os serviços, iniciavam os convites aos profissionais para participar da pesquisa, ao aceitarem era marcado dia e horário para sua realização e essas ocorriam em salas fechadas para manter o sigilo. 
As rodas de conversa iniciavam pelo preenchimento da ficha sócio demográfica, momento em que o pesquisador orientava os participantes no preenchimento dessa ficha, primeiro coletivamente e já respondendo as dúvidas que surgiam, depois de forma individual, junto aos participantes que apresentavam maior dificuldade para compreender o instrumento. Após a finalização dessa etapa dava-se início a roda pela pergunta inicial referente ao conhecimento deles sobre RD.

\section{Procedimentos de Análise dos Dados}

Após a transcrição do material gravado, entrevistas e rodas de conversa, a primeira etapa foi descrever o funcionamento das instituições. Utilizou-se como fonte principal as entrevistas com coordenadores, complementadas por informações dos demais técnicos, das observações livres e, no caso da CT, da sua página na internet. A segunda etapa foi a organização do material transcrito em duas categorias pré-estabelecidas, de acordo com os objetivos específicos da pesquisa, sendo essas: conceituação da RD e práticas em RD.

A partir dessa categorização, foram sistematizadas primeiramente as entrevistas com os profissionais. Os resultados referentes aos profissionais do CAPSad III e da CT são apresentados separadamente na seção dos resultados, uma vez que os conteúdos das falas têm características distintas. Por sua vez, a categorização das rodas de conversa com os usuários de ambas as instituições se mostrou complementar para a compreensão da $\mathrm{RD}$, assim são apresentadas conjuntamente e, quando necessário, faz-se o apontamento da característica especifica que distingue uma instituição da outra. Optou-se por essa abordagem para evitar a repetição dos resultados e visualizar melhor o discurso dos usuários relacionado ao discurso institucional.

Após essas duas etapas, elegemos um analisador para orientar as discussões dos dados. Um analisador é aquilo que faz surgir o que não está visível numa instituição, é um acontecimento que, de uma só vez, permite apreender o que atravessa os diferentes discursos (Lourau, 1993). Assim, para a emergência dos analisado- res, utilizamos a análise do discurso, realizada com base nos pressupostos teóricos de Foucault (1979/2009, 1970/2010), em que assumimos o discurso baseado em duas características. Primeiro, o discurso não é entendido como uma oposição a práticas "reais", mas os discursos conectam, sustentam modos de ser e fazer sobre o mundo. Segundo, as falas dos sujeitos da pesquisa, seus enunciados, não são uma construção individual e elas não surgem de um processo racional dialético de reflexão sobre os diferentes argumentos e sua aproximação à verdade. Ao invés disso, compreendemos o enunciado como a expressão de um agenciamento de forças, um agenciamento sempre coletivo e, muitas vezes, composto de elementos contraditórios.

Assim, o analisador busca apontar as diferentes forças constituintes dessas instituições, que são expressas por meio dos discursos dos sujeitos que fazem parte do serviço; logo, o discurso nos interessa por ser um caminho para explorar esse campo que ultrapassa as concepções individuais sobre o uso abusivo de álcool e outras drogas, operam para a sustentação dos serviços, mas indicam as possibilidades de mudança.

\section{Resultados}

\section{Perfil do Usuário}

Trata-se de um grupo heterogêneo, composto majoritariamente pelo gênero masculino, 61 dos 63 sujeitos, com idade entre 30 e 50 anos (Média $=39,69$; Desvio Padrão $=10,9)$ e renda de até dois salários mínimos. Verificou-se que os participantes têm histórico de mais de um tratamento (em média mais de 3 tentativas) e que fazem uso principalmente de álcool $(35,7 \%)$, seguido do crack (21,4\%). Nenhum usuário relatou dependência somente a cannabis.

\section{Instituições}

A primeira instituição pesquisada foi o CAPSad III. Sua organização fundamenta-se nos princípios da reforma psiquiátrica brasileira e na RD. É um serviço aberto e comunitário que deve acolher qualquer pessoa, de ambos os sexos, e 
disponibiliza sete leitos para internações de até quinze dias. Para isso, conta com equipe multiprofissional composta de 34 técnicos e equipe de apoio (cozinheira, porteiro, auxiliares de serviços gerais). A equipe técnica atua conjuntamente na realização de triagens, grupos terapêuticos, orientação aos familiares, avaliação dos casos e elaboração do projeto terapêutico singular, em parceria com o usuário, além da condução geral da rotina do serviço. Além disso, são realizadas consultas médicas (clínica geral e psiquiatria), atendimentos psicológicos e distribuição de medicamentos pela equipe de enfermagem, que também disponibiliza cuidados aos usuários internados. Em média, são atendidas mensalmente 130 pessoas, realizadas 20 triagens e 10 re-triagens, o que indica uma alta rotatividade de usuários.

A segunda instituição pesquisada foi uma CT, essa é uma associação religiosa reconhecida pela Igreja Católica destinada ao abrigo de dependentes químicos e que opera sobre o tripé trabalho, convivência e espiritualidade. Suas unidades são divididas em feminina e masculina e a internação ocorre por um período de doze meses. Para entrar na CT é necessário que a pessoa escreva uma carta expondo os motivos que o levaram a procurar a instituição e pagar mensalidade equivalente a um salário mínimo durante a estadia. As visitas de familiares ocorrem uma vez por mês, a partir do terceiro mês de internação. A equipe responsável é formada por cinco voluntários responsáveis pela manutenção da rotina diária dos 30 internos, mas a capacidade máxima é de 70 pessoas. O dia inicia às $6 \mathrm{~h} 30 \mathrm{~min}$ com a reza do terço; têm duas sessões de trabalho, uma pela manhã e outra à tarde, totalizando cinco horas, e, no momento da pesquisa, as atividades de trabalho eram: retirar da mata varas para construir cercas, recolher cajus e castanhas do pomar, fazer doce de caju, cuidar da horta, fazer pão e cozinhar; são distribuídas quatro refeições diárias e o dia encerra às $22 \mathrm{~h}$. Durante 2012 houve 79 internações na CT, dessas, somente 15 permaneceram por um ano, indicando resistência dos usuários em completar o ciclo de tratamento da instituição.

\section{A RD segundo Profissionais do CAPSad III}

A RD é considerada pelos profissionais como uma diretriz fundamental do serviço, uma vez que os usuários têm inúmeras recaídas e abandonos durante o tratamento. Assim, o que pode ser almejado pela instituição é a diminuição dos problemas de saúde relacionados ao uso excessivo de drogas, sendo a abstinência alcançada somente na minoria dos casos. Para os técnicos do CAPSad III toda a diminuição do uso de drogas é RD. Porém, apesar desse discurso, os profissionais não identificam o serviço como um espaço de operacionalização da RD, uma vez que não trabalham diretamente com a proposta. Os profissionais caracterizam a RD como uma das alternativas que podem compor suas estratégias de ação, mas a consideram estratégia menos complexa e mais barata, contrapondo-se aos tratamentos tradicionais que têm como objetivo a abstinência, aos quais consideram superiores e que constituem a meta atual do serviço.

Os princípios da $\mathrm{RD}$ que operam atualmente no CAPSad III são: autonomia dos usuários em relação aos objetivos do tratamento; atendimento humanizado e acolhimento mesmo sob efeito de SPA's; ações de reinserção social junto à família e o auxilio na busca de atividade profissional. É possível observar que não se trata de proposições exclusivas e características da política de RD, mas são diretrizes gerais da política brasileira de saúde mental. Aquelas que incluem os momentos de uso como foco das intervenções não são identificadas como ações oficiais do CAPSad III, ainda que possam ser utilizadas, de acordo com a necessidade do caso, como, por exemplo, a substituição do uso de crack por maconha.

Os técnicos consideram que apesar de alguns usuários se beneficiarem ou ser a única alternativa possível para outros, tal prática de RD conflita com os objetivos do CAPSad III, indicando a dificuldade de superar perspectivas moralizantes em relação ao consumo de SPA's. Ademais, não registramos ações de RD como: promoção de trocas de seringas, agulhas e inaladores descartáveis, disponibilização de informações sobre os riscos associados ao consumo, 
especialmente sobre infecções por HIV e Hepatite $\mathrm{C}$ entre consumidores de drogas injetáveis, e de outras possibilidades de tratamento na RAPS. A falta de informações e suporte técnico sobre $\mathrm{RD}$, seus princípios, intervenções e como operacionalizá-la no serviço é um dos resultados mais evidentes da pesquisa. Ou seja, o CAPSad III encontra-se defasado em termos do que vem sendo desenvolvido em nível mundial em relação a RD. Isso reforça concepções moralizantes acerca dos usuários de SPA's, impede o desenvolvimento de estratégias pragmáticas e condizentes com os objetivos dos usuários, dificultando, assim, a operacionalização da RD.

\section{A RD segundo Profissionais da CT}

Os profissionais da CT não reconhecem a $\mathrm{RD}$ como uma diretriz possível para compor sua metodologia de trabalho. Enfatizam em seus discursos aspectos negativos da $\mathrm{RD}$, sugerindo que ela pode, em longo prazo, atuar na manutenção da dependência química, pois não tem a abstinência como objetivo a ser alcançado. Dessa forma, a RD facilitaria o consumo e estimularia a prática de atividades ilegais para obter drogas. Além dessa perspectiva distorcida acerca da RD, nota-se que todo o potencial preventivo e promotor de saúde que a RD traz é desconsiderado no âmbito da CT. A proposta terapêutica de internação na CT, implica, segundo os coordenadores, em uma mudança profunda de vida. Continuar com o consumo, mesmo de drogas "leves", a exemplo da maconha, não altera a condição de dependente, que seguiria numa vida vazia e sem possibilidades de desenvolvimento pessoal. Logo, a RD é compreendida como um tratamento de baixa qualidade, uma vez que não solucionaria o problema de forma definitiva. Entende-se que essa proposta seria um ato contra a dignidade do ser humano, inviabilizando por completo suas possibilidades de ação e crescimento.

\section{A RD segundo os Usuários do CAPSad III e $C T$}

Quanto às concepções sobre a $\mathrm{RD}$, foi marcante o desconhecimento da proposta. Diante desse quadro de desinformação, foram apresen- tados pelo pesquisador alguns princípios da $\mathrm{RD}$, tais como: a abstinência não ser um pré-requisito para receber cuidados das equipes de saúde; o atendimento mais acolhedor dos profissionais com os usuários e ampliação das intervenções relacionadas ao consumo de SPA's que, nessa perspectiva, podem incluir informações e distribuição de equipamentos para o consumo seguro. Questionou-se, posteriormente, acerca das mudanças ocorridas após início do tratamento em termos de saúde, trabalho e relações familiares. No CAPSad III os usuários compreendem essas mudanças, como retomar a vida laboral e/ou assumir responsabilidades junto aos familiares, como consequências do tratamento que recebem no serviço. Já na $\mathrm{CT}$ elas são atribuídas à providência divina, uma vez que estão vivendo a palavra de Deus.

Em ambas instituições os participantes ressaltam a qualidade da atenção recebida, que durante sua trajetória de vida como usuários de SPA's sofreram com marginalização e preconceitos, mas que nessas instituições foram acolhidos com respeito e tratados com cuidado pelos profissionais e companheiros de tratamento. Salienta-se que, somente no CAPSad III, isso pode ser estendido aos momentos em que ocorrem o consumo dessas substâncias.

No tocante às práticas utilizadas pelos usuários das duas instituições para diminuição dos danos devido ao consumo de AD, esses consideram não ser possível fazer o uso moderado de álcool, cocaína ou crack, apesar do desejo de fazer o uso ocasional dessas substâncias, retomando uma época de suas vidas em que se divertiam, sem enfrentar maiores problemas devido ao consumo. Afirmam que ao tentar utilizar esporadicamente, acabam por retomar o uso compulsivo.

Foram feitas algumas considerações sobre a implicação de assumir o consumo como uma via possível dentro do tratamento. Dessa forma, as situações de utilização de álcool e drogas, nomeadas como "recaídas" e consideradas inevitáveis pelos usuários, não seriam tão desastrosas se tivessem como meta a RD e não a abstinência. Somente no grupo referente à $\mathrm{CT}$, a moral religiosa como fundamento do tratamento foi considerada um aspecto que pode ampliar os efeitos 
negativos de uma nova ocasião de uso de álcool e drogas, já que a orientação religiosa condena fortemente essas situações, reforçando a tendência dos usuários em se esconder ou não buscar ajuda. Estratégias como não compartilhar utensílios para o consumo, fumar crack no cachimbo em vez da lata, alimentar-se durante o período de uso foram mencionadas somente em uma roda de conversa no CAPSad III. A situação mais frequentemente encontrada sobre práticas de RD diz respeito às estratégias criadas para evitar situações de risco e mudança de foco, uma vez que se compreende que não consumir SPA's é reduzir danos. Compartilhar essas estratégias com o grupo apareceu como uma ação importante para evitar novas ocasiões de consumo.

Um ponto de destaque sobre as estratégias pessoais de RD, presente somente entre os usuários do CAPSad III é a relação que se estabelece com o uso dos medicamentos psicotrópicos prescritos pelos médicos do serviço. Ao iniciar a discussão sobre RD, o primeiro exemplo levantado foi a tentativa de diminuir o consumo dos medicamentos psiquiátricos. Considerado pelos usuários um ponto positivo do CAPSad III, pois nessa instituição (em oposição aos hospitais psiquiátricos) os medicamentos servem apenas como um suporte durante os momentos mais dificeis, salientando os efeitos colaterais negativos que seu uso em excesso pode trazer. A percepção sobre os prejuízos que o uso excessivo de medicação pode causar, principalmente frente ao preconceito que dependentes químicos sempre gostariam de receber mais drogas, legais ou ilegais, foi um aspecto importante dessa pesquisa. Essas falas dizem da autonomia dos usuários e capacidade de crítica sobre o uso da medicação prescrita.

Outra questão identificada é que a substituição (cocaína/crack pela maconha) não foi encontrada entre os participantes da pesquisa. Com exceção de um usuário que revelou fazer uso de cannabis, os demais relataram não ter vontade de fumar, assumem que anteriormente eram consumidores de maconha e foi comum o relato do uso conjunto com o crack. Porém, o uso conjunto de álcool e crack foi relatado pela maioria, dessa forma, os usuários apontam que é central manter-se abstêmio do álcool para controlar a dependência ao crack. Por fim, não identificamos intervenções em ambos serviços de acompanhamento dos usuários durante o período de consumo.

\section{Discussão dos Resultados}

A pesquisa revelou que a RD é vista como uma estratégia menos complexa e mais barata, contrapondo-se aos tratamentos tradicionais que têm como objetivo a abstinência, que é a meta dos dois serviços pesquisados. A RD não é operacionalizada no dia a dia por profissionais enquanto estratégia de informação acerca das possibilidades de tratamento na RAPS, de redução de consumo, prevenção de riscos associados, promoção da saúde e introdução nos programas de inserção social. Dessa forma, consideramos esse ser o grande analisador do estudo.

Inicialmente, os discursos das duas equipes podem parecer antagônicos, uma vez que o CAPSad III se coloca como apoiador dessa proposta e a CT nega-a completamente como uma diretriz. Aspectos como o atendimento humanizado e a autonomia dos usuários que foram ressaltados pelo CAPSad III são elementos que não contrariam os princípios da $\mathrm{CT}$, como foi observado anteriormente.

Assim, tem-se uma situação em que a RD é considerada um importante elemento para o trabalho do CAPSad III, enquanto diretriz de saúde, mas suas intervenções são desconsideradas, sendo uma opção de ação somente quando não é possível alcançar a abstinência. Mota (2012) obteve resultados semelhantes ao constatar que profissionais adicionam elementos da $\mathrm{RD}$ em seus discursos, contudo, continuam a sustentar que para uma vida saudável não deve ocorrer nenhum consumo de SPA's. Ainda de acordo com a autora, a prática desses profissionais buscaria exercer o controle sob o usuário, controle legitimado pelo poder do conhecimento científico e pautado sobre a ideia das drogas enquanto um agente portador de grave ameaça à sociedade, portanto, que devem ser combatidas.

Detectamos que os profissionais de ambas as instituições não utilizam a $\mathrm{RD}$ enquanto es- 
tratégia de promoção de saúde e não operacionalizam no cotidiano dos serviços espaços de discussão sobre essa proposta, ou intervenção junto aos usuários. Porém, os usuários mostram-se muito mais permeáveis às novas estratégias de ação nessa perspectiva. As falas dos internos da CT sobre o beneficio que teriam ao receber atendimento no CAPSad III indicam nessa direção, assim como as estratégias pessoais para enfrentar dificuldades vivenciadas no tratamento, que podem incluir momentos de consumo de SPA's.

$\mathrm{O}$ tratamento moral constitui-se como o princípio de ação das duas instituições. Nele ocorre a condenação do consumo de álcool e outras drogas e aumenta-se a responsabilização do sujeito, tanto como causador da sua dependência química, quanto pela mudança da sua situação de vida (Marlatt \& Gordon, 1993). Essas questões estão em consonância com as fragilidades das políticas de redução de danos no Brasil, sendo essas: a precarização do trabalho dos profissionais, ausência ou dificuldade de monitoramento das ações desenvolvidas, dificuldade de vincular os usuários ao um tratamento continuado e problemas de financiamento que afetam a sustentabilidade dos serviços (Inglez-Dias, Ribeiro, Bastos, \& Page, 2014). Dessa maneira, a união desses fatores, conjuntamente com a ausência de espaços de atualização técnica e supervisão institucional, contribuem para a manutenção do discurso moral.

Nessa forma de compreender o tratamento de consumidores de $\mathrm{AD}$ a experiência da recaída não é tolerada. O próprio uso desse termo, recaída, indica um atravessamento entre o campo da saúde e a moral religiosa. Poderiam ser utilizados outros termos para caracterizar essa nova ocasião de consumo de $\mathrm{AD}$, entretanto, recair expõe não um problema de saúde, mas antes disso, é uma queda da alma, que se deixaria levar pelas tentações e desvia-se do caminho da "salvação", ao retornar aos prazeres vazios das drogas. Essas sempre associadas ao desejo de morte, descuido com a saúde e criminalidade (Souza \& Carvalho, 2012).

Logo, enquanto a abstinência é salvação e saúde, as contínuas recaídas que acontecem durante o tratamento são vistas como doença, sendo esse comportamento que as instituições querem modificar para recuperar o dependente químico. Assim, a função das instituições é fazer que o sujeito (re)adquira o controle sobre suas decisões e comportamentos, perdido devido ao seu estado de dependência. E para realizar essa função utilizam dois mecanismos: o fortalecimento psíquico e a subversão do pedido.

O primeiro relaciona-se à abstinência como a meta a ser atingida. Para tal, o tratamento busca instalar uma atitude de controle que, aliada à concepção de que a dependência química é uma doença sem cura, deverá ser mantida para sempre. As técnicas terapêuticas têm por objetivo fortalecer o controle psíquico dos usuários (psicotrópicos para diminuir ansiedade, terapia em grupo, consultas) e treinar atitudes mentais e comportamentais de esquiva frente às situações de risco. Os usuários devem passar a viver num estado de vigília constante, para não deixar a tentação às drogas crescer e retomar o controle (Tedesco, 2012).

O segundo mecanismo, subversão do pedido, refere-se à resposta dada ao sujeito que procura ajuda na CT. O usuário procura a comunidade para que essa o auxilie a solucionar seus problemas com o consumo excessivo de álcool e/ou drogas. Porém, ao acolher esse sujeito, essa subverteria seu pedido inicial, propondo uma modificação de vida que vai muito além do uso de drogas. Ela inclui a aceitação de uma ideologia religiosa e a modificação (quase) completa da sua maneira de entender e reagir ao mundo. Enfim, uma mudança profunda de si, das suas relações, da sua vida (Tinoco, 2006).

Comumente, tende-se a caracterizar o trabalho do CAPSad III com o primeiro mecanismo e a CT com o segundo. Entretanto, os dois atuam de maneira integrada em ambas as instituições na medida em que o CAPSad III busca criar estratégias para evitar recaídas (deixar de frequentar determinados ambientes, desfazer amizades) e opera na busca por desfazer as crenças "disfuncionais" desse sujeito. Assim, qualquer sentimento e experiência de aceitação às drogas deve ser repensado e a rotina diária do usuário é avaliada para que não ocorram momentos que favoreçam o consumo. Logo, apesar de não ser 
um pedido explicito, o tratar-se implicaria aceitar essa modificação.

A proposta da CT desde o inicio é aceitar uma mudança profunda na vida. Todavia, para realizar essa mudança a comunidade também faz uso de ferramentas de fortalecimento, como: grupos de apoio, compartilhamento de experiências e estratégias de controle do desejo por drogas. Assim, o tratamento à drogadição nas duas instituições não é apenas a remissão de um sintoma, ou modificação do comportamento de consumo de $\mathrm{AD}$, mas uma modificação profunda na subjetividade e nos modos de vida, que deve ser realizada sobre uma verdade única, a negação do consumo de SPA's. Assim, as pessoas que não tomam a abstinência como meta do seu tratamento, não terão uma proposta de intervenção adequada à sua necessidade, sendo um dos fatores que contribui para o abandono do tratamento pelos usuários.

A experiência de recaída traz sentimentos de fraqueza e medo, age ao manter o sujeito num estado de tensão permanente para afastar-se das drogas e produz a dependência química como uma doença incurável e cíclica. Devido a essas características, torna-se necessário o apoio constante das instituições, públicas ou privadas, para operar a (re)construção de um sujeito livre de drogas (Tedesco, 2012). Entretanto, essa ocorre sempre em relação às drogas, isto é, deve-se aumentar a vigilância para evitar a sua reutilização. Assim, o processo de subjetivação desse sujeito é marcado por uma relação contínua de oposição ao desejo por drogar-se e de submissão às regras de controle. Regras que implicariam uma negação da própria vida para abster-se das drogas, ou, assumir que sua vida anterior não é válida e que agora deverá seguir outro caminho.

Ao assumir uma clínica que tem como foco evitar recaídas, estão excluídas outras dimensões desse campo de relações. Está eliminado o trabalho clinico sobre a experiência do drogar-se ou não resistir às drogas e não é possível adentrar nesse campo de forças a fim de problematizar quais são as outras relações possíveis para além de uma abstinência total ou do consumo exagerado (Tedesco, 2012). Essa experiência, segundo a autora, se não eliminada por completo, é inclu- ída para servir de contraponto ao 'bem' que é estar abstêmio.

Mesmo com usuários adultos, com anos de consumo de diferentes drogas, a discussão não pode ser iniciada sem ter como direção final a negação dessa experiência como possibilidade de vida. É como se pudesse ser passada uma mensagem errada (drogas são boas), ou perder uma chance de mudar essa situação ao legitimar o discurso dos usuários. Então, aproveita-se o momento da recaída, em que a pessoa se encontra debilitada e propensa a assumir seus erros, para reforçar a submissão às regras de controle. Logo, ao mesmo tempo em que deve ser combatida, é ela que funciona como sustentação do programa de tratamento. Esse analisador nos aponta a direção do discurso legitimado como verdade, pois tanto profissionais quanto usuários caracterizam a recaída como inevitável, recorrente e destruidora. Porém, um discurso hegemônico sempre suscita forças de resistência, sendo que essas são expressas de maneiras diferentes nas instituições.

$\mathrm{Na} \mathrm{CT}$, a possibilidade de aceitar a recaída está excluída. Apesar dos portões estarem abertos, é um local de internação e há revistas para a entrada na comunidade. Assim, os riscos de acontecer o consumo de AD são minimizados, uma vez que é necessária uma fuga da instituição e, para o usuário retornar à comunidade, ele deve aceitar seu erro e fazer um pedido de recomeço. O CAPSad III atua no fortalecimento dos sujeitos para evitarem as recaídas. Porém, o serviço não exclui quando essas acontecem; pelo contrário, ao se ter uma recaída é pedido que a pessoa compareça a instituição. Assim, na medida em que os usuários não conseguem manter-se abstinentes, eles forçam na instituição uma abordagem que inclua o uso, forçam o confronto com a RD.

Como observado por Marlatt e Witkiewitz (2002), o pedido inicial do usuário é uma vida livre de drogas, porém, passados alguns meses, é comum incluírem algum consumo moderado em suas metas. Contudo, apesar de não se ter uma intervenção institucional que opere nessa perspectiva, abrem-se espaços para resistências a isso. $\mathrm{O}$ usuário não pode ser expulso por causa 
do consumo. Na verdade, quanto mais problemas existirem relacionados ao uso de álcool e drogas, maior devem ser os cuidados ofertados pelo CAPSad III, podendo incluir o acolhimento noturno. Dessa forma, encontra-se no CAPSad III um embate entre o tratamento moral, que tem a abstinência como o objetivo a ser alcançado, e a política de atenção psicossocial, embasada na $\mathrm{RD}$, que propõe a adequação dos serviços às necessidades dos usuários, tendo no projeto terapêutico singular o instrumento técnico símbolo dessa proposta.

Assim, os discursos que encontramos no CAPSad III revelam contradições. Ao contrário da CT, esse serviço não cria perfis de clientes a serem atendidos, mas busca atender a todos com demanda relacionadas ao consumo de AD. No cenário atual, em que ocorre mudança para funcionamento 24 horas, o aumento de usuários de crack e a entrada de moradores de rua, os profissionais do CAPSad III questionam-se sobre a reformulação que a instituição necessita, sem saber como operá-la e qual direção seguir.

\section{Considerações Finais}

É marcante a diferença no entendimento sobre RD entre profissionais e usuários. Enquanto os profissionais compreendem essa abordagem como a permissão para alguma forma de consumo de SPA's, atitude essa moralmente rechaçada, por sua vez, os usuários a compreendem por meio das modificações positivas que obtiveram em sua vida, após o inicio do tratamento. Isso indica que os usuários são mais permeáveis às intervenções em RD e, além disso, têm uma atitude menos condenatória em relação ao consumo de $\mathrm{AD}$.

Constatamos nessa pesquisa que a proposta da $\mathrm{RD}$ não tem sido utilizada ou discutida nos serviços, fato que era esperado para a $\mathrm{CT}$, mas não para o CAPSad III. Além disso, a lógica moral continua a ser o principal discurso que subsidia as intervenções. Apesar disso, identificamos serviços que buscam mudanças, reforçando o atendimento humanizado como central para suas ações e sendo avaliadas positivamente pelos seus usuários. Também nos deparamos com a si- tuação de precarização das instituições que não deve ser menosprezada, pois ela interfere diretamente na qualidade do atendimento prestado.

Para além da não adequação dos espaços físicos às necessidades de profissionais e usuários, não encontramos indicação da existência de qualquer atividade de capacitação no CAPSad III ou tentativa de inserção das políticas públicas de atenção psicossocial na CT. Nesse campo de atuação que envolve tanto questões técnicas, quanto valores morais, a capacitação e a supervisão institucional se tornam ações imprescindíveis para a adequação dos serviços às demandas que recebem. Finalizando, constatamos que a proposta de RD não está sendo utilizada como uma ferramenta potencializadora de mudanças no campo de atenção aos usuários de $\mathrm{AD}$.

O questionamento que fica é se essa proposta continua a ser uma via de enfrentamento às estratégias de controle e exclusão social que operam através da questão das drogas, ou se ela foi incorporada ao discurso vigente, através da compreensão que qualquer intervenção com o objetivo de diminuir o consumo individual pode ser RD. Tornando-a, assim, uma via de atualização dos mesmos processos moralizantes e de marginalização a que ela busca se opor.

O fato do estudo não ter tido como objetivo avaliar a operacionalização das práticas de $\mathrm{RD}$, sugere a necessidade de ampliação futura. Logo, os problemas apontados, bem como a compreensão dos sujeitos acerca dessa técnica, devem ter características distintas quando confrontadas com sua prática no cotidiano. As informações de como essa população reage e utiliza a RD é de suma importância para desenvolver protocolos de tratamento adequados às necessidades da equipe e dos usuários.

\section{Referências}

Afonso, M. L., \& Abade, F. L. (2008). Para reinventar as rodas. Belo Horizonte, MG: Rede de Cidadania Mateus Afonso Medeiros. Recuperado em http:/www.novamerica.org.br/ medh2/arquivos/reinventar_rodas.pdf

Alarcon, S. (2012). A Síndrome de Elêusis: Considerações sobrea as políticas públicas no 
campo de atenção ao usuário de álcool e outras drogas. In S. Alarcon \& M. A. S. Jorge (Eds.), Álcool e outras drogas: Diálogos sobre um mal-estar contemporêneo (pp. 45-62). Rio de Janeiro, RJ: Fundação Oswaldo Cruz.

Amaral-Sabadini, M., Saitz, R., \& Souza-Formigoni, M. L. (2010). Do attitudes about unhealthy alcohol and other drug (AOD) use impact primary care professionals' readiness to implement AOD-related preventive care? Drug and Alcohol Review, 29, 655-661. doi:10.1111/j.14653362.2010.00222.x

Bastos, F. I., Karam, M. L., \& Martins, S. M. (2003). Drogas, dignidade e inclusão social: A lei e a prática de reduçao de danos. Rio de Janeiro, RJ: Associação Brasileira de Redutores de Danos.

Breakwell, G. M., Fife-Schaw, C., Hammond, S., \& Smith, J. A. (2010). Métodos de pesquisa em psicologia. Porto Alegre, RS: Artes Médicas.

Canadian AIDS Society. (2008). Learning from each other: Enhancing community-based harm reduction programs and practices in Canada. Ottawa: Author. Retrieved from http://www. canadianharmreduction.com/project/pdf/final report_en.pdf

Comissão Global de Políticas Sobre Drogas. (2011). Guerra às drogas. Recuperado em http://www. globalcommissionondrugs.org/reports/

Data SUS. (2015) Cadastro Nacional dos Estabelecimentos de Saude. Brasília, DF. Recuperado em http://tabnet.datasus.gov.br/cgi/tabcgi.exe?cnes/ cnv/estabbr.def

Dias, M. K. (2012). Dispositivos de atenção em saúde mental e seus desafios: Os impasses na consolidação de uma rede. Natal, RN: Editora Universidade Potiguar.

Escohotado, A. (1998). Historia general de las drogas. Madrid: Alianza Editorial.

European Monitoring Centre for Drugs and Drug Addiction. (2005). Illicit drug use in the EU: legislative approches. Lisbon: Author. Retrieved from http://www.emcdda.europa.eu/html.cfm/ index34041EN.html

Fontanella, B. J. B., \& Turato, E. R. (2005). Spontaneous harm reduction: A barrier for substancedependent individuals seeking treatment? Revista Brasileira de Psiquiatria, 27(4), 272-277. Recuperado em http://www.scielo.br/pdf/rbp/ v27n4/a04v27n4.pdf
Foucault, M. (2009) Microfísica do poder (R. Machado,Trad.). Rio de Janeiro, RJ: Graal. (Original publicado em 1979)

Foucault, M. (2010) A ordem do discurso: Aula inaugural no Collège de France, pronunciada em 2 de dezembro de 1970 (20. ed., L. F. A. Sampaio,Trad.). São Paulo, SP: Loyola. (Original publicado em 1970)

Hunt, N. (2003). A review of the evidence-base for harm reduction approaches to drug use. Retrieved from http://www.neilhunt.org/publications.htm

Inglez-Dias, A., Ribeiro, J. M., Bastos, F., \& Page, K. (2014). Políticas de redução de danos no Brasil: Constribuições de um programa norte-americano. Ciência \& Saúde Coletiva, 19(1), 147-157.

Jelsma, M. (2009). Legislative innovation in drug policy: Latin American initiative on drugs and democracy. Transnational Institute. Retrieved from http:/www.ungassondrugs.org/images/ stories/legislativeinnovation.pdf

Levine, H. G. (2003). Global drug prohibition: Its uses and crises. International Journal of Drug Policy, 14, 145-153. doi:10.1016/S09553959(03)00003-3

Lopez, R. B., Onyemekwu, C., Hart, C. L., Ochsner, K. N., \& Kober, H. (2015). Boundary conditions of methamphetamine craving. Experimental and Clinical Psychopharmacology. Advance online publication. Retrieved from http://dx.doi. org/10.1037/pha0000049

Lourau, R. (1993). Análise institucional e práticas de pesquisa. Rio de Janeiro, RJ: Editora da Universidade do Estado do Rio de Janeiro.

Marlatt, G. A., \& Gordon, J. R. (1993). Prevenção de recaida: Estratégias de manutenção no tratamento de comportamentos adictivos. Porto Alegre, RS: Artes Médicas.

Marlatt, G. A., \& Witkiewitz, K. (2002). Harm reduction approaches to alcohol use : Health promotion, prevention, and treatment. Addictive Behaviors, 27(1), 867-886. doi:10.1016/S03064603(02)00294-0

Ministério da Saúde. (2004). A política do Ministério da Saúde para atenção integral a usuários de álcool e outras drogas. Brasília, DF: Secretaria de Atenção à Saúde. Recuperado em http://www. obid.senad.gov.br/portais/OBID/biblioteca/documentos/Legislacao /326983.pdf 
Mota, V. L. (2012). Representação Social da Redução de Danos para profissionais que atuam pelo Programa Mais Vida da cidade do Recife (Dissertação de mestrado, Programa de PósGraduação em Psicologia, Universidade Federal de Pernanbuco, Recife, PE, Brasil).

Nadelmann, E. (2005). Los daños de la prohibición de las drogas en las américas. Retrieved from http://www.bvsde.paho.org/bvsacd/cd66/09. nadelman.pdf

Newcombe, R. (1992). The reduction of drug related harm: A conceptual framework for theory, practice and research. Retrieved from: http:// www.researchgate.net/publication/230704511_ The_reduction_of_drug-related_harm_a_ conceptual_framework_for_theory_practice_ and_research

Passos, E. H., \& Souza, T. P. (2011). Redução de danos e saúde pública: Construções alternativas à política global de "guerra às drogas". Psicologia \& Sociedade, 23(1), 154-162. Recuperado em http://www.scielo.br/pdf/psoc/v23n1/ a17v23n1.pdf

Portaria $\mathrm{n}^{\mathrm{o}}$ 3.088, 23 de dezembro de 2011. (2011). Institui a Rede de Atenção Psicossocial para pessoas com sofrimento ou transtorno mental e com necessidades decorrentes do uso de crack, álcool e outras drogas, no âmbito do Sistema Único de Saúde (SUS). Brasília, DF: Ministério da Saúde. Recuperado em http:// bvsms.saude.gov.br/bvs/saudelegis/gm/2011/ prt3088_23_12_2011_rep.html

Resolução CONAD No 01/2015. (2015) Regulamenta, no âmbito do Sistema Nacional de Políticas Públicas sobre Drogas, as entidades que realizam o acolhimento de pessoas, em caráter voluntário, com problemas associados ao uso nocivo ou dependência de substância psicoativa, caracterizadas como comunidades terapêuticas. Brasília, DF: Conselho Nacional de Políticas Sobre Drogas. Recuperado em http://www.mprn.mp.br/portal/transformandodestinos-arquivos/legislacao-1/resolucoes1/3499-resolucao-conad-no-012015-1/file

Rodrigues, L. B. F. (2006). Controle penal sobre as drogas ilícitas: o impacto do proibicionismo no sistema penal e na sociedade (Tese de doutorado, Departamento de Direito Penal, Medicina Legal e Criminologia, Universidade de São Paulo, São Paulo, SP, Brasil).
Secretária Nacional de Políticas sobre Drogas. (2013). Censo das comunidades terapêuticas no Brasil. Brasília, DF: Autor. Recuperado em http://www.mapa-ct.ufrgs.br/

Souza, T. P. (2007). Redução de danos no Brasil: A clínica e a política em movimento (Dissertação de mestrado, Programa de Pós-Graduação em Psicologia, Universidade Federal Fluminense, Niterói, RJ, Brasil).

Souza, T. P., \& Carvalho, S. R. (2012). Reduzindo danos e ampliando a clínica: Desafios para a garantia do acesso universal e confrontos com a internação compulsória. Polis \& Psique, 2(Número temático), 37-58. Recuperado em http://seer.ufrgs.br/index.php/PolisePsique/article/view/40319/25628\#

Tedesco, S. H. (2012). Pensando a ética da clínica das drogas: Linguagem, subjetivação e a experiência das drogas (Tese para concurso de professor titular de psicologia social e institucional, Departamento de Psicologia, Univerdidade Federal Fluminense, Niterói, RJ, Brasil).

Tinoco, R. (2006). Comunidades terapêuticas livres de drogas: Da intervenção ideológica à intervenção psicoterapêutica. Revista Toxicodependências, 12(1), 21-30. Recuperado em http:// comum.rcaap.pt/bitstream/123456789/3112/1/ Comunidades\%20terapeuticas.pdf

Vadhan, N. P., Hart, C. L., Haney, M., Gorp, W. G., \& Foltin, R. W. (2009). Decision-making in long-term cocaine users: Effects of a cash monetary contingency on Gambling task performance. Drug and Alcohol Dependence, 102, 95-101. doi:10.1016/j.drugalcdep.2009.02.003

Werb, D., Rowell, G., Guyatt, G., Kerr, T., Montaner, J., \& Wood, E. (2011). Effect of drug law enforcement on drug market violence: A systematic review. International Journal of Drug Policy, 22(2), 87-94. doi:10.1016/j. drugpo.2011.02.002 